\title{
Richtlijnen voor het onderwijs in de medische vervolgopleidingen: waarom en hoe?
}

\author{
Th.J. ten Cate, M. Horsman, S.J. van Luijk, F. Scheele
}

\section{Samenvatting}

Richtlijnen, mits op de juiste wijze toegepast, kunnen een waardevolle rol vervullen in het bijdragen aan de kwaliteit van het medisch onderwijs. Binnen het In VIVO-project worden richtlijnen ontwikkeld om het leren en toetsen op de werkplek te ondersteunen en de gebruikers ervan de mogelijkheid te geven deze richtlijnen naar hun eigen context te vertalen.

De richtlijnen betreffen uiteenlopende aspecten van de medische vervolgopleidingen en in het bijzonder die aspecten die volgens de nieuwe regelgeving verplicht zijn, maar waarvoor nog niet veel aanwijzingen voor de uitvoering beschikbaar zijn.

Een richtlijn ontwerpen is lastig. De ervaring leert dat een stapsgewijze aanpak nuttig is. Deze stappen zijn achtereenvolgens; 1) maken van een inhoudsopgave, 2) afbakenen van het onderwerp, 3) verrichten van een literatuurstudie, 4) definiëren van gebruikte begrippen, 5) bespreken van de achtergronden, 6) opnieuw beoordelen van de indeling van de richtlijn en 7) een kritische beoordeling door externe deskundigen.

Een richtlijn die klaar is wordt beoordeeld door een NVMO-reviewcommissie. In dit artikel wordt ingegaan op de criteria die deze commissie van plan is te hanteren. Cate ThJ ten, Horsman M, Luijk SJ van, Scheele F. Richtlijnen voor het onderwijs in de medische vervolgopleidingen: waarom en hoe? Tijdschrift voor Medisch Onderwijs 2008;27(6):272-278.)

\section{Inleiding: de twee zijden van richtlijnen}

Richtlijnen hebben iets goeds en iets gevaarlijks in zich. Goed is dat deskundigen zich buigen over een onderwerp en 'good practices', evidence en eventueel eigen onderzoek betrekken bij een verantwoord advies over het handelen. Er is een referentiekader voor het handelen en wie nieuw is op het terrein kan erop terugvallen. Een goede richtlijn maakt het werk leuker en beter. Gevaarlijk wordt het als een richtlijn het zelf nadenken met gezond verstand gaat vervangen. Evidence based richtlijnen in de geneeskunde zijn niet bedoeld om clinici het denkwerk uit handen te nemen maar juist om dit te versterken. Dat richtlijnen het eerste soms wel veroorzaken is bekend. In de klinische geneeskunde is mechanistisch uitvoeren van richtlijnen natuurlijk verwerpelijk, maar, zo kan men tegenwerpen, als een practicus een richtlijn volgt zonder de relevante achtergronden helemaal te doorgronden, is dat misschien toch verantwoord als de juiste beslissing maar wordt genomen. Dat ligt nog iets anders bij opleidingsrichtlijnen. Een leersituatie is bij uitstek een interactief proces, waarin degene die opleidt en degene die opgeleid wordt samen de opleiding vormgeven. Als opleiden vooral het uitvoeren van richtlijnen wordt, is de opleiding snel ten dode opgeschreven. Richtlijnen moeten dus vooral hulpmiddelen zijn, 'scaffolds' in onderwijsjargon, om het opleiden makkelijker en beter te maken. Contraproductief kan het worden als anderen dan opleiders en opgeleidenen deze richtlijnen tot uitgangspunt van beleid gaan maken en aan 
de uitvoering van deze richtlijnen zware consequenties gaan verbinden voor de opleiding of de arts in opleiding tot specialist (aios). Het ziekenhuismanagement of de overheid zou bij de toepassing van de richtlijnen voor de vervolgopleidingen deze rol op zich kunnen nemen. Dat moet niet leiden tot defensief opleiden, zoals ook het strikt volgen van de regels en richtlijnen om sancties te voorkomen leidt tot defensieve geneeskunde. Op andere dan universitaire onderwijsniveaus is genoeg ervaring met de demotiverende werking van richtlijnen voor het werk van professionals. ${ }^{1}$

Bent $\mathrm{u}$ al ontmoedigd? Nee? Dan hebt $\mathrm{u}$ gelijk. Want richtlijnen zijn goed, zolang ze de creativiteit van opleiders vergroten en niet verkleinen. Er is een fraaie theorie over de stimulering van intrinsieke motivatie, de 'Self-determination' theorie, die ons leert dat de combinatie van drie zaken - gevoel van competentie, gevoel van autonomie en gevoel van verbondenheid c.q. van waardering vanuit de sociale omgeving - een krachtige motor is voor de ontwikkeling van intrinsieke motivatie. ${ }^{2}$ Dat geldt voor zowel de aios als de opleider, c.q. voor iedereen die betrokken is bij het opleiden van aios. Een opleidingsrichtlijn kan het gevoel van competentie vergroten, moet de autonomie vergroten door nieuwe inzichten te geven die de opleider kan toepassen, en moet leiden tot een opleiding die door iedereen gewaardeerd wordt. Als dat lukt, beantwoordt de richtlijn aan zijn doel.

\section{Richtlijnen in het medisch onderwijs en bij het opleiden}

Sinds enkele jaren verschijnen in de literatuur steeds meer richtlijnen, aanwijzingen en handleidingen voor de praktijk van het medisch onderwijs. De Association for Medical Education in Europe (AMEE) publiceert sinds enkele jaren 'AMEE gui- des' over uiteenlopende onderwerpen. De Best Evidence Medical Education organisatie (BEME) stimuleert sinds enkele jaren de ontwikkeling van gedegen literatuurreviews die aanknopingspunten moeten bieden voor verantwoorde keuzes in het medisch onderwijs. ${ }^{3}$ De Britse vereniging voor medisch onderwijs 'Association for the Study of Medical Education' (ASME) geeft de serie 'Understanding medical education' uit met samenvattingen van de belangrijkste literatuur. ${ }^{4}$

Ook het Tijdschrift voor Medisch Onderwijs is een uitstekende bron van informatie, maar opleidingsrichtlijnen zijn hierin nog niet verschenen. Buiten de huisartsgeneeskundige sector is er nog geen Nederlandse traditie in het publiceren van landelijke opleidingsrichtlijnen. Hierin is het In VIVO-project een van de initiatiefnemers.

De richtlijn heeft de status van een hulpmiddel voor verantwoord opleiden. Het is geen regelgevend document en er moet uiteraard van afgeweken kunnen worden. Sterker nog, iedere opleidingslocatie zal een eigen opleidingsbeleid moeten voeren waarin zowel de locale context als de richtlijnen voor het opleiden een rol hebben. Zoals klinische richtlijnen leiden tot locale protocollen voor het handelen op klinische afdelingen geldt dat ook voor opleidingsrichtlijnen.

\section{De In VIVO-opleidingsrichtlijnen in voorbereiding}

Het In VIVO-projectteam definieert een richtlijn als 'een document met uitspraken over effectief en efficiënt onderwijs ter ondersteuning van de dagelijkse leermomenten binnen de gezondheidszorg, berustend op resultaten van wetenschappelijk onderzoek en een kritische beoordeling ervan, gericht op het expliciteren van goed onderwijs'. ${ }^{5}$ Omdat het In VIVOproject specifiek gericht is op de medi- 
sche vervolgopleidingen zijn de In VIVOrichtlijnen daar uiteraard op gericht.

De aanbevelingen in de richtlijn zijn in deze visie duidelijk geformuleerd en gebaseerd op wetenschappelijke bewijsvoering, concreet en specifiek. De aanbevelingen van de richtlijn zijn makkelijk op te volgen. Ze passen binnen bestaande normen en waarden in de praktijk. De toepassing van de richtlijn moet slechts op beperkte schaal nieuwe kennis en vaardigheden vereisen en geen fundamentele verandering in de organisatie of in bestaande routines en gewoonten. De toepassing van de richtlijn moet geen negatieve gevoelens oproepen bij de gebruikers en moet, waar nodig, ondersteund worden met hulpmiddelen voor de gebruikers. De onderwerpen die het In VIVO-projectteam zich voorstelt te ontwikkelen in de komende jaren zijn samengevat in tabel 1.

Tabel 1. In VIVO-opleidingsrichtlijnen in ontwikkeling, waarbij voortschrijdend inzicht nog voor enkele wijzigingen zal zorgen.

\begin{tabular}{|c|c|}
\hline Onderwerp & Ontwikkelteam \\
\hline $\begin{array}{l}\text { Observatie (evt. via video) en beoordeling op de werkvloer } \\
\text { (Korte praktijkbeoordeling - KPB) }\end{array}$ & UMC Utrecht, UMC St Radboud Nijmegen \\
\hline $\begin{array}{l}\text { Observatie (evt. via video) en beoordeling in de chirurgische praktijk } \\
\text { (Objective Structured Assessment of Technical Skills - OSATS) }\end{array}$ & AMC Amsterdam, LUMC Leiden \\
\hline Opleiding aan de operatietafel en training van vaardigheden & VUmc Amsterdam \\
\hline 360 Graden observatie & UMC Utrecht, AMC Amsterdam \\
\hline Toetsresultaten interpreteren & Maastricht UMC \\
\hline Beoordeling van het portfolio & $\begin{array}{l}\text { Maastricht UMC, Erasmus MC Rotterdam, } \\
\text { UMC Groningen }\end{array}$ \\
\hline Feedback geven & UMC St Radboud Nijmegen \\
\hline Voortgangsbespreking & LUMC Leiden \\
\hline Opstellen individuele opleidingsschema's & UMC Utrecht, Erasmus MC Rotterdam \\
\hline Doelmatige inzet van docentprofessionalisering & UMC Groningen \\
\hline Het gebruik van bekwaamheidsverklaringen & VUmc Amsterdam \\
\hline Kwaliteitsborging in de specialistenopleiding & In VIVO-projectteam \\
\hline
\end{tabular}


Deze richtlijnen zullen vooral gaan functioneren als ook de wetenschappelijke verenigingen en KNMG colleges - Centraal College Medische Specialismen (CCMS), College voor Huisartsgeneeskunde en Verpleeghuisgeneeskunde (CHVG) en College voor Sociale Geneeskunde (CSG) met hun registratiecommissies - zich erin kunnen vinden.

\section{Handvatten voor het schrijven van een richtlijn}

Het opstellen van opleidingsrichtlijnen is makkelijker voorgenomen dan uitgevoerd. Het In VIVO-projectteam heeft al in 2007 aan In VIVO-kernteams in de diverse regio's de opdracht gegeven een serie richtlijnen te ontwerpen. Na anderhalf jaar is er één richtlijn af; andere richtlijnen zijn in de maak, maar het ontwerpen kost meer tijd en moeite dan veelal gedacht is. Daarom volgen hier enkele suggesties voor de aanpak, ontleend aan een recente In VIVO-notitie. ${ }^{6}$

\section{Algemene aanwijzingen}

- Het is verstandig als één of twee hoofdauteurs initiatiefnemer zijn, het meeste schrijfwerk doen en de eindredactie hebben. Daarnaast is er een team (of redactiecommissie) dat op tussenproducten commentaar kan leveren.

- Een goede start is een brainstorm over zoveel mogelijk vragen die beantwoord zouden moeten worden in de richtlijn. Deze worden geordend en die ordening dient als voorlopige inhoudsopgave.

- Omdat de richtlijn voor zover mogelijk op literatuur gebaseerd moet zijn, is het verstandig iemand te zoeken die de beschikbare literatuur gaat verzamelen en samenvatten. Geschikt is een basisarts of ouderejaars student geneeskunde die ervaring heeft met lite- ratuuronderzoek, al dan niet gekoppeld aan een wetenschappelijke stage of aan lopend promotieonderzoek.

- Baseer de aanbevelingen over de onderdelen van de richtlijn die niet op basis van literatuur beantwoord kunnen worden, op logische argumentatie, op het oordeel van deskundigen en zo nodig op eigen onderzoek.

- Houd steeds rekening met de bruikbaarheid in de praktijk van de richtlijnen.

- Maak de aanwijzingen niet te ingewikkeld en houd steeds de weinig ingevoerde, maar welwillende gebruiker voor ogen.

- De richtlijn moet een breed draagvlak krijgen. Daarom is het belangrijk dat concept richtlijnen en/of de erin beschreven procedures door gezaghebbende personen of groepen zijn gezien of toegepast. Deze fase en de rapportage erover behoort deel uit te maken van de richtlijn.

- Het spreekt vanzelf dat richtlijnen een document in ontwikkeling blijven. Binnen enkele jaren na de introductie en toepassing is evaluatie en bijstelling op zijn plaats. Dat is niet alleen nodig op basis van de ervaringen ermee, maar ook omdat de context en regelgeving van de opleidingen kunnen veranderen.

\section{Stappenplan voor het schrijfproces van een richtlijn}

\section{Stap 1: Maken van een voorlopige inhoudsopgave}

Maak een lijst met alle mogelijke vragen die men vanuit het perspectief van de opleider of de aios graag beantwoord zou zien in de richtlijn. Stel bij voorkeur in eerste instantie met één of twee personen een lijst op en vul die aan met hulp van andere experts. Later kan de lijst verder 
aangevuld worden, bijvoorbeeld na literatuurstudie of na beperkt onderzoek. Voorbeelden zijn:

- Wat wordt er bedoeld met het begrip / het instrument / de methode?

- Wat is het doel van het instrument / de methode, waarom deze methode te gebruiken?

- Wie gaat het instrument / de methode gebruiken en voor wie is het bedoeld?

- Op welke wijze kan het instrument / de methode toegepast worden (organisatie, procedures)?

- Wanneer / hoe vaak wordt het instrument / de methode toegepast (frequentie, opleidingsfase)?

- Waar gaat het instrument / de methode ingezet worden (context, specifieke situaties, bij alle aios)?

- Welke stappen zijn nodig voor de implementatie (zoals instructie en training van aios en opleiders, scheppen van randvoorwaarden).

\section{Stap 2: Afbakenen van het onderwerp}

Enige overlap tussen de verschillende opleidingsrichtlijnen is onvermijdelijk. De suggestie is in een vroeg stadium inhoudsopgave en conceptversies van richtlijnen uit te wisselen en te overleggen over de consistentie van de aanbevelingen. Zo kan de richtlijn 'Beoordeling portfolio' (OOR Maastricht, Rotterdam, Groningen) meer toegespitst zijn op inhoud en psychometrie en de richtlijn 'Voortgangsbespreking' (OOR Leiden) de rol van het portfolio voor beoordeling en feedback bespreken.

\section{Stap 3: Doen van een literatuurstudie}

Goede aanwijzingen voor een literatuurstudie voor een richtlijn zijn te vinden in het rapport van het Centraal Begeleidingsorgaan van de Intercollegiale Toetsing (CBO) 'Evidence-based Richtlijnontwikkeling' dat gratis is te verkrijgen. ${ }^{7}$
Stap 4: Definiëren van begrippen

Wat wordt verstaan onder de besproken onderwerpen? Hanteer internationaal gangbare terminologie, bespreek synoniemen, maak een beargumenteerde keuze en stel zo nodig Nederlandse termen voor.

\section{Stap 5: Bespreken van achtergronden}

Is de theorie of ratio van een methode/onderwerp richtlijn samen te vatten? Een korte ontstaansgeschiedenis kan toegevoegd worden indien dat verhelderend is. Overige onderwerpen zijn:

- Zijn er lacunes in de wetenschappelijke literatuur?

- In hoeverre zijn resultaten van de literatuurstudie toepasbaar op de Nederlandse situatie?

- Zijn bestaande instrumenten bruikbaar of moeten nieuwe instrumenten ontworpen en/of gevalideerd worden?

- Behalve wetenschappelijke literatuur zijn vaak ook voorbeelden te vinden uit de praktijk, bijvoorbeeld instrumenten en reeds toegepaste procedures.

\section{Stap 6: Opnieuw indelen van de richtlijn}

Beschrijf de conclusies en samenvatting van de literatuur ten aanzien van de verschillende vragen of onderwerpen die bedacht zijn bij stap 1. Dit leidt tot herordening van de inhoudsopgave tot een logisch geheel. De richtlijn kan nu omgezet worden in twee delen: de eigenlijke richtlijn, die niet meer dan drie of vier pagina's moet beslaan, en de verantwoording, die zo beknopt als mogelijk maar zo uitgebreid als nodig moet zijn. De verantwoording is een referentiedocument dat vooral geraadpleegd wordt om de achtergrond van de richtlijn te begrijpen.

\section{Stap 7: Kritisch beoordelen}

Hierbij worden uiteraard eerst de richtlijnredactieleden betrokken, maar ook andere deskundigen en practici zijn nuttig 
hierbij. Dat leidt tot iteratieve bijstellingen. Als de richtlijn presentabel is wordt deze voorgelegd aan de NVMO-reviewcommissie Opleidingsrichtlijnen.

\section{Stap 8: Schrijven van aanbevelingen}

Bij de aanbevelingen worden de vragen, oorspronkelijk bedacht bij stap 1, zo goed als mogelijk beantwoord. Veel richtlijngebruikers zullen vooral kijken naar de aanbevelingen in de richtlijn. Het is daarom belangrijk dat aanbevelingen de uitgangsvragen beantwoorden, op zichzelf staand gelezen kunnen worden en niet voor meerdere uitleg vatbaar zijn.

\section{De NVMO-reviewcommissie voor opleidingsrichtlijnen}

De Nederlandse Vereniging voor Medisch Onderwijs is door het In VIVO-projectteam gevraagd een gezaghebbende, onafhankelijke reviewcommissie in te stellen om richtlijnen te accrediteren voordat zij gepubliceerd worden. Deze commissie is ingesteld* en heeft een voorlopige lijst van beoordelingscriteria opgesteld, onder meer ontleend aan het protocol voor de beoordeling van een richtlijn voor het klinisch handelen volgens het model "Appraisal of Guidelines for Research \& Evaluation (AGREE). ${ }^{8}$ Deze zijn samengevat in tabel 2.

Tabel 2. Criteria voor de beoordeling van een opleidingsrichtlijn.

- Doel van de richtlijn

(wat is het probleem waarvoor deze richtlijn een oplossing biedt?)

- Toepasselijkheid

(zijn de aanbevelingen van toepassing in de meeste opleidingen?)

- Begrijpelijkheid voor de doelgroep

(begrijpelijke taal voor opleiders, opleidingsteam, stafleden, aios? Worden begrippen goed gedefinieerd en uitgelegd?)

- Fundering

(gebaseerd op evidence en belangrijkste literatuur voor zover beschikbaar?)

- Logica

(zijn de aanbevelingen face-valide en met gezond verstand te verdedigen?)

- Uitvoerbaarheid en acceptabiliteit

(zijn de aanbevelingen uitvoerbaar en is er draagvlak te verwachten bij opleiders, aios, KNMG-colleges en registratiecommissies?)

- Volledigheid

(worden de vragen beantwoord die leven bij de doelgroep?)

- Beknoptheid

(beperkt de richtlijn zich tot de essentie?)

- Kosten, opofferingen en organisatorische consequenties

(zijn deze besproken? Is ook het patiëntenperspectief meegenomen?)

- Breedte en context

(worden alternatieve benaderingen besproken en afgewogen?)

- Instructie en training

(instructie, communicatie, training behalve over wat ook over hoe het moet gebeuren)

- Implementatie

(is er een invoeringstraject beschreven? Is er voorzien in een pilotprocedure?)

- Updating

(hoe wordt de richtlijn geëvalueerd en bijgesteld?)

* Prof. dr. Paul Stuyt, internist; Dr. Marlies Schijven, chirurg; Dr. Mario Maas, radioloog; Dr. Anneke Kramer, huisarts; Dr. Cor Postma, internist; Prof. dr. Th. J. ten Cate, medisch-onderwijskundige 


\section{Samenvattend}

Met dit In VIVO-proces wordt beoogd een stelsel van richtlijnen te ontwikkelen dat de kwaliteit van de Nederlandse vervolgopleiding maximaal bevordert; richtlijnen die ook nog bekend zijn in het veld als het In VIVO-project allang is vergeten. Een gevaarlijke ontwikkeling? Wij denken van niet, mits de richtlijnen worden gebruikt waarvoor ze zijn bedoeld: een hulpmiddel voor een betere kwaliteit van opleiden.

\section{Dankwoord}

Dank aan de leden van de NVMO-reviewcommissie Opleidingsrichtlijnen voor het commentaar bij een eerdere versie van dit artikel.

\section{Literatuur}

1. Mulder H. Wil je meten en beheersen, of geef je mensen de kans hun persoon met de professie te verbinden? In gesprek met Fred Korthagen. In: Van den Brink $G$ et al. (red.) Beroepszeer waarom Nederland niet goed werkt. Amsterdam: Boom; 2005.

2. Ryan RM, Deci EL. Self-determination theory and the facilitation of intrinsic motivation, social development, and well-being. American Psychologist 2000;55(1):68-78.

3. http://www.bemecollaboration.org/beme/pages/ index.html. [bezocht op 8 augustus 2008].

4. http://www.asme.org.uk/. [bezocht op 8 augustus 2008].
5. Kenmerken van en criteria voor richtlijnen. Notitie In VIVO, februari 2008.

6. Horsman MA, Ten Cate ThJ. Suggesties voor het opstellen van een opleidingsrichtlijn. InVIVO, 13 februari 2007.

7. Evidence-based Richtlijnontwikkeling - Handleiding voor werkgroepleden. Kwaliteitsinstituut voor de Gezondheidszorg CBO. November 2007. http://www.cbo.nl/product/richtlijnen/handleiding_ebro/. [bezocht op 8 augustus 2008].

8. The AGREE Collaboration. Appraisal of Guidelines for Research \& Evaluation (AGREE) Instrument. www.agreecollaboration.org. en http://www.cbo.nl/ product/richtlijnen. [bezocht op 8 augustus 2008].

De auteurs:

Prof. dr. Th. J. ten Cate, hoogleraar medische onderwijskunde en directeur Expertisecentrum voor Onderwijs en Opleiding, UMC Utrecht.

Mw. drs. M. Horsman, huisarts en onderzoeker in opleiding, UMC Utrecht.

Dr. S.J van Luijk, senior beleidsmedewerker, Instituut voor Onderwijs en Opleiden, VUmc Amsterdam. *

Prof. dr. F. Scheele, gynaecoloog, St. Lucas Andreas Ziekenhuis, Amsterdam."

* allen zijn lid van het In VIVO-projectteam

Correspondentieadres:

Prof. dr. Th.J. ten Cate, Expertisecentrum voor Onderwijs en Opleiding, UMC Utrecht, postbus 85500, 3508 GA Utrecht.E-mail: t.j.tencate@umcutrecht.nl

Belangenconflict: geen gemeld

Financiële ondersteuning: geen gemeld

\section{Summary}

Practice guidelines can be helpful to enhance the quality of medical education, but should be used cautiously, as they should not inhibit the creativity of programme directors and supervisors. The Dutch "In VIVO" project guides the frontrunners of the modernisation of postgraduate medical training in Obstetrics/Gynaecology and Paediatrics. It has issued several 'guidelines of good educational practice', covering a wide range and addressing educational measurement instruments as well as topics of educational practice and quality appraisal. The aim is to enhance the quality of workplace-based learning and assessment. In this article eight steps to guide the writing of guidelines are discussed: (1) create a table of contents, covering all questions that might be raised about the topic; (2) define the scope of the topic; (3) carry out a systematic literature search, (4) define all relevant concepts related to the topic; (5) discuss backgrounds and context; (6) review the structure of the guideline and split it into a 2-4 page guideline and backgrounds, as extensive as necessary; (7) have experts critically review the guidelines; (8) write recommendations.

The procedure and criteria to be used by an NVMO review committee in appraising educational guidelines are discussed. (Cate ThJ ten, Horsman MA, Luijk SJ van, Scheele F. Guidelines for postgraduate medical training: why and how? Dutch Journal of Medical Education 2008;27(6):272-278.) 